\title{
MANEJO DO NITROGÊNIO EM COBERTURA DO FEIJOEIRO DE INVERNO NO SISTEMA PLANTIO DIRETO
}

\section{FLÁVIO FERREIRA DA SILVA BINOTTI ${ }^{1}$, ORIVALDO ARF ${ }^{2}$, ELIANA DUARTE CARDOSO ${ }^{1}$, MARCO EUSTÁQUIO DE SÁ ${ }^{2}$, SALATIER BUZETTI ${ }^{2}$}

\footnotetext{
${ }^{1}$ UEMS/Cassilândia, MS, binotti@uems.br, elianaduarte@uems.br. ${ }^{2}$ UNESP/Ilha Solteira, SP, arf@agr.feis.unesp.br, mesa@agr.feis.unesp.br, sbuzetti@agr.feis.unesp.br.
}

\begin{abstract}
RESUMO: O nitrogênio é o nutriente absorvido em maior quantidade pela cultura do feijoeiro e vários trabalhos têm evidenciado seu efeito positivo na produtividade. $\mathrm{O}$ manejo da adubação nitrogenada de cobertura é de vital importância para aumentar a eficiência da planta na utilização do $\mathrm{N}$ e aumentar produtividade. O objetivo foi avaliar o efeito da época de aplicação e fontes de nitrogênio em cobertura no crescimento e produtividade do feijoeiro de inverno. O projeto foi instalado no município de Selvíria (MS), no período de outono-inverno (2003) em solo classificado como Latossolo Vermelho Distrófico. O delineamento experimental foi o de blocos casualizados com 12 tratamentos constituídos pela combinação de três fontes de nitrogênio (sulfato de amônio, uréia e mistura de sulfato de amônio $1 / 2$ do $\mathrm{N}+$ ureia $1 / 2$ do $\mathrm{N}$ ) e diferentes épocas de aplicação de nitrogênio em cobertura (testemunha - sem $\mathrm{N}, 20,30$ e $20+30$ dias após emergência das plântulas), na dose de $80 \mathrm{~kg} \mathrm{ha}^{-1}$ de $\mathrm{N}$, com quatro repetições. $\mathrm{O}$ feijoeiro não apresentou diferenças na produtividade de grãos em relação à utilização de diferentes fontes e épocas de aplicação de nitrogênio em cobertura, entretanto a aplicação de nitrogênio em cobertura proporcionou, em média, um aumento de $19 \%$ na produtividade de grãos comparado com a testemunha sem $\mathrm{N}$ em cobertura.
\end{abstract}

PALAVRAS CHAVE: Phaseolus vulgaris L., fonte de nitrogênio, sulfato de amônio, ureia, época de aplicação e parcelamento de $\mathrm{N}$.

\section{SIDEDRESSING NITROGEN FERTILIZER MANAGEMENT OF WINTER COMMON BEAN IN NO TILLAGE}

\begin{abstract}
ABSTRATC: Nitrogen is the most absorbed nutrient by common bean crop and several works have shown its positive effect on yield. Sidedressing nitrogen fertilization is very important to increase the nitrogen plant use efficiency and unable higher crop productivity. Thus, this research had as objective, to evaluate the effect of application time and nitrogen sources at sidedressing on development and yield of irrigated winter common bean in no tillage system. The trial was conducted in Selvíria (Mato Grosso do Sul State), in autumnwinter 2003, in a typical dystrophyc Haplustox. A randomized complete block design was used with 12 treatments constituted by combination of three nitrogen sources (ammonium sulphate, urea and ammonium sulphate $1 / 2$ of $N+$ urea $1 / 2$ of $N$ ) in different application times of sidedressing nitrogen (control - without N, 20,30 and $20+30$ days after seedling emergency), in dose of $80 \mathrm{~kg} \cdot \mathrm{ha}^{-1}$ of $\mathrm{N}$, with four repetitions. The common bean was not affected in its yield by nitrogen sources and application times. On the other hand, sidedressing nitrogen provided, on average, an increase of $19 \%$ in the yield compared with control without sidedressing nitrogen application.
\end{abstract}

KEY-WORDS: Phaseolus vulgaris L., nitrogen source, ammonium sulphate, urea, application time and nitrogen installment. 


\section{INTRODUÇÃO}

A cultura do feijoeiro (Phaseolus vulgaris L.) é de grande importância na composição de sistemas agrícolas. Neste contexto, a utilização de técnicas que visem aumentar sua produtividade de grãos tem sido objetivo de vários estudos. O nitrogênio é o nutriente absorvido em maior quantidade pela planta. Segundo Oliveira et al. (1996) quantidades superiores a $100 \mathrm{~kg} \mathrm{ha}^{-1}$ de $\mathrm{N}$ são requeridas para garantir a extração do nutriente associada a altas produtividades de grãos. O consumo de fertilizantes no ano de 2013 foi de aproximadamente 31 milhões de toneladas, evidenciando um aumento a cada ano que passa, pois em 2011 e 2012 o consumo foi de 29 e 28 milhões de toneladas, respectivamente (ANDA, 2014).

Por ser um elemento afetado por uma dinâmica complexa e não deixar efeitos residuais diretos das adubações, o manejo da adubação nitrogenada é um dos mais difíceis (RAIJ, 1991). Vários são os fatores que afetam a eficiência da adubação nitrogenada em cobertura, sendo três deles considerados de maior importância para o produtor: a fonte de nitrogênio a ser utilizada, a quantidade e o método a ser empregado para sua aplicação.

A deficiência de nitrogênio no solo pode ser corrigida aumentando sua disponibilidade no solo, por meio da aplicação de fertilizante nitrogenado. De acordo com Barbosa Filho e Silva (2001) sulfato de amônio e ureia apresentam baixa eficiência de utilização pelas culturas, raramente superior a $50 \%$, mas são as mais utilizadas na agricultura brasileira. De acordo com ANDA (2014) a quantidade de saca de $60 \mathrm{~kg}$ de feijão necessária para adquirir uma tonelada de fertilizante foi de 10,86 em 2011, 7,46 em 2012, 6,76 em 2013 e 11,7 em 2014.

A baixa exigência de $\mathrm{N}$ no período inicial de crescimento das plantas possibilita perdas por lixiviação, além de uma possível queda da porcentagem de germinação das sementes, pela maior salinização no sulco de semeadura, em decorrência da utilização de uma dose elevada de $\mathrm{N}$, comprometendo o estande inicial, podendo acarretar menor produtividade do feijoeiro. Assim, as culturas anuais recebem na semeadura apenas uma fração da dose total do $\mathrm{N}$ que necessitam e o restante é aplicado em cobertura sobre o solo.

Soratto et al. (2001) verificaram que é vantajosa a aplicação de nitrogênio em cobertura e as maiores produtividades de grãos foram obtidas com aplicação do nitrogênio em cobertura aos 15 ou aos 25 dias após a emergência (DAE), e redução da produtividade com a aplicação tardia aos 35 DAE. Gomes Junior et al. (2005) verificaram que a adubação nitrogenada de cobertura deve ser realizada até o $7^{\circ}$ trifólio totalmente aberto na haste principal.

A adoção de um manejo adequado da adubação nitrogenada em cobertura levando em consideração a época de aplicação, com ou sem parcelamento e a fonte de $\mathrm{N}$ a utilizar na cultura do feijão de inverno irrigado em sistema plantio direto, pode ser de suma importância no sentido de oferecer maior segurança e precisão para o produtor nas ações de manejo da adubação nitrogenada em cobertura, além de aumentar a eficiência da planta na utilização dos recursos disponíveis, evidenciando a possibilidade de aumentar a produtividade de grãos do feijoeiro.

Assim, a pesquisa foi desenvolvida com o objetivo de avaliar o efeito de diferentes fontes e épocas de aplicação de nitrogênio em cobertura no crescimento e produtividade de grãos do feijoeiro de inverno irrigado, cultivado no sistema plantio direto. 


\section{MATERIAL E MÉTODOS}

O cultivo do feijoeiro foi realizado na área experimental da Universidade Estadual Paulista (UNESP) - Campus de Ilha Solteira, localizada no município de Selvíria (MS), no período de outono-inverno de 2003, com irrigação (aspersão convencional). O solo é classificado como Latossolo Vermelho Distrófico argiloso (EMBRAPA, 2006). Os resultados da análise química do solo na camada de 0 a $20 \mathrm{~cm}$ foram: MO: $37 \mathrm{~g} \mathrm{dm}^{-3}$, P (resina): $18 \mathrm{mg}$ $\mathrm{dm}^{-3}, \mathrm{pH}\left(\mathrm{CaCl}_{2}\right): 5,0 ; \mathrm{K}, \mathrm{Ca}, \mathrm{Mg}$ e $\mathrm{H}+\mathrm{Al}: 2,0 ; 21 ; 14$ e $33 \mathrm{mmol}_{\mathrm{c}} \mathrm{dm}^{-3}$, respectivamente, e V $=53 \%$. A precipitação média anual é de $1370 \mathrm{~mm}$, a temperatura média anual é de $23,5^{\circ} \mathrm{C}$ e a umidade relativa do ar entre 70 e $80 \%$ (média anual).

$\mathrm{O}$ delineamento experimental foi em blocos casualizados, em esquema fatorial $3 \mathrm{x} 4$, constituído por três fontes de nitrogênio (ureia, sulfato de amônio e mistura $-1 / 2$ de $\mathrm{N}$ ureia + $1 / 2$ de $\mathrm{N}$ do sulfato de amônio) e diferentes épocas de aplicação de nitrogênio em cobertura (testemunha - sem N, 20, 30 e $20+30$ dias após emergência das plântulas - DAE), na dose de $80 \mathrm{~kg} \mathrm{ha}^{-1}$ de $\mathrm{N}$, com quatro repetições. Na aplicação parcelada do $\mathrm{N}$ aplicou-se $50 \%$ (40 $\mathrm{kg} \mathrm{ha}^{-1}$ ) aos 20 DAE e o restante aos 30 DAE. As parcelas foram constituídas por cinco linhas de $6,0 \mathrm{~m}$ de comprimento espaçadas de $0,50 \mathrm{~m}$ entre si. A área útil foi constituída pelas três linhas centrais, desprezando-se $0,50 \mathrm{~m}$ em ambas as extremidades de cada linha.

A semeadura foi realizada em área anteriormente cultivada com arroz de terras altas. A área foi dessecada, utilizando-se o herbicida glyphosate (1930 $\mathrm{g} \mathrm{ha}^{-1}$ do i.a.) três dias antes da semeadura. O feijão foi semeado, mecanicamente, no dia 13/04/2003 utilizando-se o cultivar IAC Carioca Eté, com 12-13 sementes viáveis por metro. As sementes receberam tratamento com fungicida - benomyl (100g do i.a. por $100 \mathrm{~kg}$ de sementes). A adubação química básica no sulco de semeadura foi calculada de acordo com as características químicas do solo e as recomendações de Ambrosano et al. (1997) e foi constituída por $15 \mathrm{~kg} \mathrm{ha}^{-1} \mathrm{de} \mathrm{N}$ (ureia), $45 \mathrm{~kg}$ ha ${ }^{-1}$ de $\mathrm{P}_{2} \mathrm{O}_{5}$ (superfosfato simples) e $30 \mathrm{~kg} \mathrm{ha}^{-1}$ de $\mathrm{K}_{2} \mathrm{O}(\mathrm{KCl})$. Nos tratamentos com aplicação do nitrogênio em cobertura, a mesma foi realizada perto da linha de semeadura em dose única ou parceladamente $\left(80 \mathrm{~kg} \mathrm{ha}^{-1}\right)$, segundo os tratamentos citados anteriormente. Após a aplicação de nitrogênio, a área foi irrigada com o objetivo de minimizar as perdas de nitrogênio por volatilização. As irrigações foram realizadas por um sistema de irrigação por aspersão convencional com aplicação de $3,3 \mathrm{~mm}$ por hora nos aspersores.

O controle de plantas daninhas foi realizado com uma aplicação do herbicida fluazifop-p-butil + fomesafen, em pós-emergência $\left(128 \mathrm{~g}+160 \mathrm{~g}\right.$ do i.a. ha $\left.{ }^{-1}\right)$. O controle e a prevenção das principais pragas e doenças na cultura foram realizados por meio de pulverizações com produtos recomendados para a cultura. A emergência das plântulas ocorreu aos 5 dias após a semeadura. Aos 45 e 87 dias após emergência das plântulas ocorreram o florescimento e a colheita do feijão, respectivamente.

Foram avaliadas as seguintes características: população de plantas (10 m de linha da área útil da parcela) inicial - realizada no estádio $\mathrm{V}_{2}$; população de plantas final (plantas ha ${ }^{-1}$ ) - realizada na colheita; fitomassa seca de 10 plantas na área útil da parcela $\left(\mathrm{g} \mathrm{planta}^{-1}\right)$ coleta realizada no florescimento; teor de nitrogênio total na parte aérea $\left(\mathrm{g} \mathrm{kg}^{-1}\right)$ - coleta realizada no florescimento; componente de produção - avaliação realizada em 10 plantas número de vagens planta ${ }^{-1}$, número de grãos planta $^{-1}$, número de grãos vagem ${ }^{-1}$, massa de 100 grãos e produtividade de grãos ( $\mathrm{kg} \mathrm{ha}^{-1}$ - avaliada em $10 \mathrm{~m}$ de linha, $13 \%$ base úmida).

Os dados foram avaliados através da análise de variância pelo teste $\mathrm{F}$ e havendo significância entre os tratamentos utilizou-se o teste de comparação de médias, Tukey com o programa SANEST (ZONTA; MACHADO, 1986). 


\section{RESULTADOS E DISCUSSÃO}

As interações entre os fatores pesquisados não foram significativas e, portanto, foram apresentados os efeitos simples dos fatores. As populações inicial e final de plantas não foram afetadas pelas fontes e épocas de aplicação do nitrogênio em cobertura (Tabela 1), o que era esperado para a população inicial de plantas, pois na época de realização dessa análise ainda não tinha ocorrido a adubação nitrogenada de cobertura.

A fitomassa seca da planta do feijoeiro não foi influenciada pelas fontes de $\mathrm{N}$, resultados que corroboram com os obtidos por Alvarez et al. (2005) e Afonso et al. (2011) que não observaram diferenças na fitomassa seca em relação à utilização de diferentes fontes de $\mathrm{N}$ em cobertura. A época de aplicação de nitrogênio, entretanto, influenciou a fitomassa seca de planta, com os valores médios na aplicação realizada aos $20 \mathrm{DAE}\left(8,79 \mathrm{~g} \mathrm{planta}^{-1}\right)$ não diferindo da aplicação parcelada do adubo nitrogenado e superior às demais épocas. É possível que o fornecimento antecipado do nitrogênio propiciou suprimento de nitrogênio adequado à demanda do feijoeiro, pois no sistema de plantio direto, ocorre uma maior demanda de nitrogênio pela cultura, devido à decomposição da palhada da cultura anterior.

Tabela 1. População inicial e final de plantas, fitomassa seca de planta, teor de $\mathrm{N}$ total da parte aérea e número de vagens por planta do feijoeiro de inverno irrigado em função do manejo do nitrogênio em cobertura. Selvíria (MS), 2003.

\begin{tabular}{|c|c|c|c|c|c|}
\hline \multirow{2}{*}{ Tratamentos } & \multicolumn{2}{|c|}{ População de Plantas } & \multirow{2}{*}{$\begin{array}{l}\text { Fitomassa } \\
\text { Seca }\end{array}$} & \multirow{2}{*}{$\begin{array}{c}\text { Teor de } \mathrm{N} \\
\text { na parte } \\
\text { aérea }\end{array}$} & \multirow{2}{*}{$\begin{array}{c}\mathrm{N}^{\mathrm{o}} \text { de vagen } \\
\text { planta }^{-1}\end{array}$} \\
\hline & Inicial & Final & & & \\
\hline & -----planta & $a^{-1} \times 1000----$ & g planta $^{-1}$ & $--\mathrm{g} \mathrm{kg}^{-1}--$ & \\
\hline \multicolumn{6}{|c|}{ Fonte de nitrogênio $\left(80 \mathrm{~kg} \mathrm{ha}^{-1}\right)$} \\
\hline Ureia & $\mathrm{M}_{243}$ & 207 & 7,19 & $24,21 \mathrm{~b}$ & 10,89 \\
\hline Sulfato de amônio (SA) & 242 & 205 & 6,80 & $28,32 \mathrm{a}$ & 10,33 \\
\hline $1 / 2$ de $\mathrm{N}$ da uréia $+1 / 2$ de N SA & 237 & 211 & 7,76 & $24,45 \mathrm{~b}$ & 11,02 \\
\hline \multicolumn{6}{|c|}{ Época de aplicação de $\mathrm{N}$ em cobertura $\left(80 \mathrm{~kg} \mathrm{ha}^{-1}\right)$} \\
\hline Testemunha $(\mathrm{sem} \mathrm{N})$ & 238 & 204 & $5,68 \mathrm{c}$ & $20,91 \mathrm{c}$ & 10,20 \\
\hline $20 \mathrm{DAE}^{1}$ & 234 & 211 & $8,79 \mathrm{a}$ & $24,98 \mathrm{~b}$ & 11,10 \\
\hline $30 \mathrm{DAE}$ & 254 & 204 & $6,93 \mathrm{bc}$ & $28,81 \mathrm{a}$ & 10,53 \\
\hline $20 \mathrm{DAE}+30 \mathrm{DAE}$ & 237 & 211 & $7,59 \mathrm{ab}$ & $27,95 \mathrm{a}$ & 11,16 \\
\hline $\mathrm{CV}(\%)$ & 10,54 & 6,55 & 22,83 & 6,23 & 17,31 \\
\hline
\end{tabular}

$\mathrm{O}$ teor de $\mathrm{N}$ na parte aérea da planta foi influenciado pelas fontes de $\mathrm{N}$ aplicado e pela época de aplicação em cobertura. A utilização do sulfato de amônio, como fonte de $\mathrm{N}$ proporcionou plantas com maior teor de nitrogênio. Este tratamento apresentou menor produção de fitomassa seca de planta (numericamente), consequentemente não teve um efeito de diluição do nitrogênio. As plantas que receberam as outras fontes de $\mathrm{N}$ (ureia e mistura) apresentaram maior fitomassa seca (numericamente) e menor teor de nitrogênio orgânico, explicado pelo efeito da diluição, semelhante ao verificado por Fernandes et al. (2005). Possivelmente, esse menor valor de teor de $\mathrm{N}$ com a utilização da ureia também seja decorrente da volatilização da amônia, devido ao aumento da atividade microbiana favorável no sistema plantio direto com resíduo de arroz. 
O efeito de diluição do $\mathrm{N}$, também, ocorreu com a época de aplicação do nitrogênio. A aplicação do $\mathrm{N}$ aos 30 DAE e parcelado aos $20+30$ DAE proporcionaram plantas com maior teor de nitrogênio e menor fitomassa seca em relação às plantas que receberam o nitrogênio aos 20 DAE (com menor teor de nitrogênio). A ausência da adubação nitrogenada em cobertura produziu plantas com o menor teor de nitrogênio $\left(20,91 \mathrm{~g} \mathrm{~kg}^{-1}\right)$ comparadas com aquelas que receberam nitrogênio em cobertura $\left(80 \mathrm{~kg} \mathrm{ha}^{-1}\right)$.

A faixa considerada adequada para a cultura de $\mathrm{N}$ é de 30 a $50 \mathrm{~g} \mathrm{~kg}^{-1}$ (folha), de acordo com Ambrosano et al. (1997), porém os dados obtidos no presente experimento são referentes à parte aérea (folhas e estruturas caulinares), que normalmente, apresentam valores inferiores aos teores foliares. $\mathrm{O}$ teor de $\mathrm{N}$, observada na parte aérea (folhas e estruturas caulinares), também pode ter ocorrido em função do resíduo orgânico no solo proveniente da cultura do arroz sendo que este proporciona uma palha com alta relação $\mathrm{C} / \mathrm{N}$, causando assim uma competição do $\mathrm{N}$ do solo entre plantas e os microrganismos na fase inicial de decomposição do resíduo orgânico.

De acordo com Raij (1991) na decomposição de resíduos orgânicos de alta relação C/N em solos, inicialmente há um consumo do nitrato existente no solo, que é incorporado ao protoplasma dos microrganismos, a matéria orgânica perde carbono, que é convertido em $\mathrm{CO}_{2}$, a relação $\mathrm{C} / \mathrm{N}$ decresce e o processo todo resulta em uma temporária imobilização líquida do nitrato do solo. Afonso et al. (2011) não observaram diferenças no teor de nitrogênio foliar em relação à utilização de diferentes fontes de $\mathrm{N}$ em cobertura.

Com relação ao número de vagens por planta se verifica na Tabela 1 que esta variável não foi influenciada pela fonte e época de aplicação de nitrogênio, o mesmo ocorrendo para o número de grãos por planta e grãos por vagem (Tabela 2). Afonso et al. (2011) não verificaram efeito das diferentes fontes de $\mathrm{N}$ (ureia e sulfato de amônio) nos componentes de produção do feijoeiro, assim como Alvarez et al. (2005) utilizando ureia e nitrato de amônio.

Tabela 2. Número de grãos e vagem por planta, massa de 100 grãos e produtividade de grãos do feijoeiro de inverno irrigado em função do manejo do nitrogênio em cobertura. Selvíria (MS), 2003.

\begin{tabular}{|c|c|c|c|c|}
\hline Tratamentos & $\begin{array}{l}\mathrm{N}^{\mathrm{o}} \text { de grãos } \\
\text { planta }^{-1}\end{array}$ & $\begin{array}{l}\mathrm{N}^{\mathrm{o}} \text { de grãos } \\
\text { vagem }^{-1}\end{array}$ & $\begin{array}{l}\text { Massa de } 100 \\
\text { grãos }\end{array}$ & Produtividade \\
\hline & & & -----g----- & ------kg ha ${ }^{-1}-----$ \\
\hline \multicolumn{5}{|l|}{ Fonte de nitrogênio $\left(80 \mathrm{~kg} \mathrm{ha}^{-1}\right)$} \\
\hline Ureia & $\mathrm{M}_{49,59}$ & 4,54 & $20,79 \mathrm{~b}$ & 1.799 \\
\hline Sulfato de amônio (SA) & 46,68 & 4,50 & $21,54 \mathrm{a}$ & 1.826 \\
\hline $1 / 2$ de $N$ da uréia $+1 / 2$ de $N$ SA & 48,97 & 4,41 & $21,43 \mathrm{ab}$ & 1.892 \\
\hline \multicolumn{5}{|c|}{ Época de aplicação de $N$ em cobertura $\left(80 \mathrm{~kg} \mathrm{ha}^{-1}\right)$} \\
\hline Testemunha $($ sem $\mathrm{N})$ & 46,55 & 4,56 & $20,54 \mathrm{~b}$ & $1.611 \mathrm{~b}$ \\
\hline $20 \mathrm{DAE}^{1}$ & 49,51 & 4,39 & $21,06 \mathrm{ab}$ & $1.886 \mathrm{a}$ \\
\hline $30 \mathrm{DAE}$ & 49,00 & 4,65 & $21,90 \mathrm{a}$ & $1.961 \mathrm{a}$ \\
\hline $20 \mathrm{DAE}+30 \mathrm{DAE}$ & 48,60 & 4,34 & $21,51 \mathrm{a}$ & $1.898 \mathrm{a}$ \\
\hline $\mathrm{CV}(\%)$ & 19,59 & 6,59 & 3,86 & 9,55 \\
\hline
\end{tabular}

${ }^{\mathrm{M}}$ Médias seguidas de letras diferentes nas colunas, dentro de cada fator, diferem estatisticamente entre si pelo teste de Tukey a $5 \% ;{ }^{1} \mathrm{DAE}$ - Dias após a emergência.

O número de grãos por vagem não sofreu influência dos tratamentos utilizados, talvez porque essa característica está mais relacionada com o cultivar utilizado sofrendo pouca 
influência das práticas culturais utilizadas na cultura, sendo que este valor está compreendido entre 4 e 5 grãos por vagem (Tabela 2). Quando se utilizou a ureia com fonte de nitrogênio a massa de 100 grãos foi de 20,79 g, valor menor em comparação com o uso do sulfato de amônio (21,54 g), porém não ocorrendo o mesmo para as épocas de aplicação do $\mathrm{N}$ que não influenciaram a massa de 100 grãos. Soratto et al. (2001) também não verificaram diferenças na massa de 100 grãos com a aplicação de nitrogênio em cobertura em diferentes épocas.

A produtividade de grãos do feijoeiro não foi afetada pelas diferentes fontes de nitrogênio utilizadas, pelo fato que na aplicação de $\mathrm{N}$ em cobertura realizou-se aplicação de uma lâmina de água de aproximadamente $10 \mathrm{~mm}$, consequentemente a ureia que poderia ser perdida por volatilização, foi incorporada ao solo, reduzindo a volatilização. $O$ enxofre contido no sulfato de amônio não influenciou a produtividade porque o feijoeiro já tinha recebido este nutriente em quantidade adequada com a adubação de semeadura (superfosfato simples). Barbosa Filho e Silva (2001), Alvarez et al. (2005) e Afonso et al. (2011) verificaram que as fontes de nitrogênio não influenciaram a produtividade de grãos do feijoeiro. A época de aplicação de nitrogênio não influenciou a produtividade de grãos do feijoeiro; o fornecimento de água de maneira controlada pode ter minimizado as possíveis perdas do N por lixiviação.

Barbosa Filho et. al. (2005) verificaram maiores produtividades de grãos com parcelamento do nitrogênio em cobertura, aos 15 e 30 DAE ou aos 15, 30 e 45 DAE em comparação em dose única aos $30 \mathrm{DAE}$, diferente do observado no presente trabalho, onde a produtividade não diferiu com o parcelamento utilizado. De acordo com Santi et al. (2013) a melhor estratégia de aplicação de $\mathrm{N}$ em cobertura foi parcelar $30 \%$ da dose aos sete dias e $70 \%$ da dose aos 35 dias após a emergência para a cultivar do grupo carioca.

A aplicação do nitrogênio em cobertura $\left(80 \mathrm{~kg} \mathrm{ha}^{-1}\right)$ proporcionou um aumento médio de $19 \%$ na produtividade de grãos $\left(304 \mathrm{~kg} \mathrm{ha}^{-1}\right)$ do feijoeiro de inverno irrigado se comparado com o tratamento que não recebeu adubação nitrogenada de cobertura (testemunha), verificando desta maneira, grande vantagem na adubação nitrogenada de cobertura.

\section{CONCLUSÕES}

O feijoeiro de inverno irrigado não apresentou diferenças na produtividade de grãos em relação à utilização de diferentes fontes de nitrogênio em cobertura.

As épocas de aplicação de nitrogênio em cobertura não influenciam a produtividade de grãos do feijoeiro de inverno irrigado.

A aplicação de $80 \mathrm{~kg} \mathrm{ha}^{-1}$ de nitrogênio em cobertura proporcionou, em média, aumento de $19 \%$ na produtividade do feijoeiro comparado com a testemunha sem $\mathrm{N}$ em cobertura.

\section{REFERÊNCIAS BIBLIOGRÁFICAS}

AFONSO, R. J.; ARF, O.; COSTA, D. S.; BARBOSA, R. M.; BUZETTI, S.; SÁ, M. E.; RODRIGUES, A. F. Combinações de fontes de nitrogênio no desenvolvimento e rendimento do feijoeiro. Pesquisa Agropecuária Tropical, Goiânia-GO, v. 41, n. 3, p. 391-398, 2011.

ALVAREZ, A. C. C.; ARF, O.; AlVAREZ, R. C. F.; PEREIRA, J. C. R. Resposta do feijoeiro à aplicação de doses e fontes de nitrogênio em cobertura no sistema de plantio direto.

Acta Scientiarum Agronomy, Maringá-PR, v. 27, n. 1, p. 69-75, 2005. 
AMBROSANO, E. J.; TANAKA, R. T.; MASCARENHAS, H. A. A.; QUAGGIO, J. A.; CANTARELLA, H. Leguminosas e oleaginosas. In: RAIJ, B. V.; CANTARELLA, H.; QUAGGIO, J.A. Recomendações de adubação e calagem para o Estado de São Paulo. 2. ed. Campinas-SP: IAC, 1997. p. 187-203 (Boletim Técnico,100).

ANDA. ASSOCIAÇÃO NACIONAL PARA DIFUSÃO DE ADUBOS. Estatística: principais indicadores do setor de fertilizantes. [s.l.: s.n.], 2014. Disponível em: <http://www.anda.org.br>. Acesso em: 24 jun. 2014.

BARBOSA FILHO, M. P.; FAGERIA, N. K.; SILVA, O. F. Fontes, doses e parcelamento da adubação nitrogenada em cobertura para feijoeiro comum irrigado. Ciência e Agrotecnologia, Lavras-MG, v. 29, n. 1, p. 69-76, 2005.

BARBOSA FILHO, M. P.; SILVA, O. F. Adubação de cobertura do feijoeiro irrigado com uréia fertilizante em plantio direto: um ótimo negócio. Informações Agronômicas, Piracicaba-SP, n. 93, p. 1-5, 2001.

EMBRAPA. EMPRESA BRASILEIRA DE PESQUISA AGROPECUÁRIA. Sistema Brasileiro de Classificação dos solos. 2. ed. Rio de Janeiro-RJ: EMBRAPA/CNPSo, 2006. p. 208.

FERNANDES, F. A.; ARF, O.; BINOTTI, F. F. S.; ROMANINI JUNIOR, A.; SÁ, M. E.; BUZETTI, S.; RODRIGUES, R. A. F. Molibdênio foliar e nitrogênio em feijoeiro cultivado no sistema plantio direto. Acta Scientiarum Agronomy, Maringá-PR, v. 27, n. 1, p. 7-15, 2005.

GOMES JUNIOR, F. G.; LIMA, E. R.; SÁ, M. E.; ARF, O.; RAPASSI, R. M. A. Rendimento do feijoeiro de inverno em resposta à época de semeadura e adubação nitrogenada em cobertura em diferentes estádios fenológicos. Acta Scientiarum Agronomy, Maringá-PR, v.27, n.1, p. 77-81, 2005.

OLIVEIRA, I. P.; ARAÚJO, R. S.; DUTRA, L. G. Nutrição mineral e fixação biológica de nitrogênio. In: ARAÚJO, R.S.; RAVA, C.A.; STONE, L.F.; ZIMMERMANN, M. J.O. (Coords.). Cultura do feijoeiro comum no Brasil. Piracicaba-SP: Potafós, 1996. p. 182-184.

RAIJ, B.V. Fertilidade do solo e adubação. São Paulo-SP: Ceres, 1991. 343 p.

SANTI, A. L.; BASSO, C. J.; LAMEGO, F. P.; FLORA, L. P. D.; AMADO, T. J. C.; CHERUBIN, M. R. Épocas e parcelamentos da adubação nitrogenada aplicada em cobertura na cultura do feijoeiro, grupo comercial preto e carioca, em semeadura direta. Ciência Rural, Santa Maria-RS, v. 43, n. 5, p.816-822, 2013.

SORATTO, R. P.; SILVA, T. R. B.; ARF, O.; CARVALHO, M. A. C. Níveis e épocas de aplicação de nitrogênio em cobertura no feijoeiro irrigado em plantio direto. Cultura Agronômica, Ilha Solteira-SP, v. 10, n. 1, p. 89-99, 2001.

ZONTA, E. P.; MACHADO, A. A. Sistema de Análise Estatística para microcomputadores - SANEST. Pelotas-RS: UFPel, Instituto de Física e Matemática, 1986. $150 \mathrm{p}$. 